\title{
The BRAVA Initiative
}

\author{
Junia Anacleto \\ LIA - Laboratório de Interação Avançada \\ Departamento da Computação - Universidade Federal de São Carlos (UFSCar) \\ São Carlos, SP, Brasil \\ junia@dc.ufscar.br
}

\begin{abstract}
The Brazilian Visual Analytics Initiative, or BRAVA, aims at leveraging the collaborative research in the field of VA promoting the networking among Brazilian and Canadian researchers. Annual BRAVA Exploratory workshops are being proposed since 2012 to provide a forum for discussions on potential research collaborative projects among Brazilians and between Brazilian and Canadian research centres.
\end{abstract}

Keywords-Visual Analytics; Visualization

\section{INTRODUCTION}

Visual Analytics is a research field that has been explored for centuries aiming to reveal knowledge and science allowing human kind to understand the universe organization, expressed by the first time in simple concentric circles around the Sun by Copernicus in $16^{\text {th }}$ century [1], some historical registers, like Egyptologists working on the Rosetta Stone since the $18^{\text {th }}$ century to interpret hieroglyphics [2], or even mythical surfaces with Galilei's draws of the mountainous and pitted surface of the Moon in early $17^{t h}$, [3]. Also, Visual Analytics has been used to facilitate learning and comprehension in classroom since $18^{\text {th }}$ century, when Joseph Priestley draw a chart of History showing a continuous flow of time, what allowed students to survey the "image of the rise, progress, extent, duration, and contemporary state of all the considerable empires that have ever existed in the world" [4], or make correlations when William Playfair proposed the graphical methods of statistics [5].

Considering that expanding the new frontiers of knowledge much depends on the way people understand the world and how it evolves, Visual Analytics plays an important role in that expansion process. Visual Analytics research in our days, or VA, is a key area for scientists to contribute to our state of knowledge. From the comprehension about how our brain can interpret what we see as well as innovative ways to visually represent data, VA researchers aim at building computer tools for people to interpret big set of data considered too complex to be analyzed using conventional tools, helping people interactively explore and synthesize information to gain insights from massive, dynamic, and often ambiguous data. VA technology is seen as of critical interest for researchers, governments and companies dealing with the phenomena of digital era known as "Big Data."

\section{BRAVA INITIATIVE}

The Brazilian Visual Analytics or BRAVA Initiative, sponsored by Boeing USA and supported by UFSCar, was launched in 2012 as an effort to leverage the VA research area in Brazil promoting discussions for potential collaboration among Brazilian researchers. BRAVA also aims to stimuli international collaboration mainly between Brazil and Canada in VA and other related research areas of Computing. Seed funding over two years from Boeing, to support workshops and a pilot project, has been provided.

BRAVA is supported by Boeing considering the company's well succeeded experience in Canada on supporting research on VA creating the Vancouver Institute for Visual Analytics (VIVA). In 2010, Boeing helped establish the Simon Fraser University/UBC joint research institute VIVA. VIVA has been considered as a model to get BRAVA off the ground.

Since 2012, BRAVA has grown to engage over 18 research centers and universities around the world in collaborations and student exchanges. Now many of these initial projects are full-fledged and ready to take off. A major collaborative project involving The University of British Columbia, OCAD University, Dalhousie University and UFScar has formed the basis for continuing ongoing cooperation, having four MOUs (memorandums of understanding) signed by UFSCar and the three Canadian universities as well as an MOU between UFSCar and GRAND, a Canadian federallyfunded Network of Centres of Excellence in digital media (http://grand-nce.ca). Another MOU is going to be signed by GRAND and Universidade de São Paulo in December 2013.

I believe that is the correct timing once VA has an strategic importance and has been chosen by the Brazilian Government as one of the 3 key areas of knowledge to consider to establish the basis for cooperation between Brazil and Canada, being discussed since 2011 by the Brazil-Canada Joint Committee for Cooperation on Science, Technology and Innovation, or Brazil-Canada 3.0.

In recent years, the Canadian and Brazilian governments have committed to stronger international cooperation targeting Information and Communication Technology (ICT). New funding opportunities such as ISTPCanada 
(Canada-Brazil Framework Agreement for Cooperation on Science, Technology and Innovation) and NSERC/FAPESP's (Natural Sciences and Engineering Research Council of Canada/Fundação de Amparo à Pesquisa do Estado de São Paulo) joint grant program provide big incentives for collaborative research, exchanges, and workshops in advanced technology.

Science and technology linkages between Brazil and Canada were further cemented in the spring of 2012 with a visit to Brazil of 30 Canadian university presidents, as members of the Association of University and Colleges of Canada (AUCC). The subsequent Canada-Brazil 3.0 Conference in João Pessoa, Brazil the following December also offered a high-level meeting of government, academic and the ICT sector representatives to discuss the economic benefits of greater internationalization in digital media research and development. BRAVA initiative is considered as an example of well-succeeded research network initiative that BrazilCanada 3.0 wants to support, aiming at replicating the experienced model beyond visual analytics.

When the BRAVA initiative was started, the primary focus was on mobile visual analytics for medical and health care applications. The research challenge has been to squeeze the needed processing power to analyze enormous amounts of data inside a small device. Especially considering the nomadic nature of those professionals' activities, they don't have the time or the space to do a deep analysis of a huge set of data they've been collecting at the health care facility. They want to access all the ability to analyze data from where they are - so on a tablet, or mobile phone.

Researchers at UBC, OCAD University, and Dalhousie University have partnered with UFSCar's Advanced Interaction Laboratory (LIA), and other Brazilian collaborators, to develop ICT solutions for long-term mental healthcare naturally inserted into the workflow considering affordances for adoption and appropriation of technologies at the workspace. The technology uses virtual presence and visual analytics to support and allow improvement on the practices at a Brazilian care facility for patients with neurological disorders.

Funding through the Microsoft Research-FAPESP Institute, CAPES and Canada's Department of Foreign Affairs and International Trade (CAPES/DFAIT), the Emerging Leaders in the Americas (ELAP) and Science Without Borders programs have helped support several short-term exchanges for Brazilian faculty and students at the partner universities.

The second BRAVA (Brazilian Visual Analytics) workshop held April 2013 in Cambury, São Paulo, came at an opportune time for Brazilian and Canadian researchers [6]. Around 50 researchers and some industry representatives from Brazil, Canada, U.S.A., the Netherlands, Singapore and the UK attended the meeting. It's the second workshop since BRAVA was launched in 2012. This second workshop showed a more expressive and mature group that knows how to look for joint research opportunities and keep the focus on international collaboration. New collaborations are being defined between UFSCar and UBC, UFRGS and DalHousie, UFG and DalHousie, UFRGS and OCAD U, UNB and OCAD U, ICMSC/USP and Purdue, POLI/USP and BOEING, POLI/USP and UBC, UFSCar and DalHousie, UFSCar and OCAD U, ICMSC/USP and DalHousie.

BRAVA has already exceeded its expectations. I believe the Initiative has shown it's capable of putting together the most distinguished Brazilian researchers on VA and related fields as well as had being able to attract Canadians researchers.

I hope we can together find our way to keep the initiative growing and getting stronger. Brazil has the potential to be one of the next world leaders and the future is in collaborative activities. Canada and Brazil are together on the journey to guide the research direction with VA.

The success of this BRAVA-led initiative has spilled over into areas of research outside visual analytics. The BRAVA initiative and the work that Boeing was supporting has grown. It's ready for new funding to support new directions.

\section{REFERENCES}

[1] (2013) De revolutionibus orbium coelestium. [Online]. Available: http://en.wikipedia.org/wiki/De_revolutionibus_orbium_ coelestium

[2] (2013) Rosetta stone. [Online]. Available: http://en.wikipedia. org/wiki/Rosetta_Stone

[3] (2013) Galileo galilei. [Online]. Available: http://en.wikipedia. org/wiki/Galileo_Galilei

[4] (2013) Joseph priestley. [Online]. Available: http: //en.wikipedia.org/wiki/Joseph_Priestley

[5] (2013) William playfair. [Online]. Available: http: //en.wikipedia.org/wiki/William_Playfair

[6] (2013) Second brava initiative workshop. [Online]. Available: http://www.lia.dc.ufscar.br/brava2013 